\title{
Expression of the Bordetella pertussis P.69 pertactin adhesin in Escherichia coli: fate of the carboxy-terminal domain
}

\author{
Ian Charles, ${ }^{1}$ Neil Fairweather, ${ }^{1}$ Derek Pickard, ${ }^{2}$ Julian Beesley, ${ }^{1}$ \\ Richard Anderson, ${ }^{3}$ Gordon Dougan ${ }^{3}$ and Mark Roberts ${ }^{2}$
}

Author for correspondence: Gordon Dougan. Tel: +44 71594 5256. Fax: +44 715945255.

1 Wellcome Research Laboratories, Beckenham, Kent BR3 3BS, UK

2,3 Medeva Vaccine Research Unit, Department of Biochemistry, ${ }^{2}$ and Department of Biochemistry, ${ }^{3}$ Imperial College of Science, Technology and Medicine, London SW7 2AZ, UK

\begin{abstract}
The mature pertactin protein (P.69) of Bordetella pertussis can be isolated from the bacterial cell surface as a polypeptide with an apparent molecular mass of $69000 \mathrm{Da}$ as determined by sodium dodecyl sulphate gel electrophoresis. However the open reading frame of prn, the pertactin gene, encodes a polypeptide with a predicted molecular mass of $93478 \mathrm{Da}$, referred to as P.93. Expression of the prn gene in Escherichia coli leads to the synthesis of the full-length P.93 polypeptide, which is rapidly processed to the mature P.69 protein located at the cell surface. The P.93 precursor polypeptide is processed at both termini. A 34 amino acid long signal sequence is removed from the amino-terminus and a polypeptide sequence of about $30000 \mathrm{Da}$ (P.30) is cleaved from the carboxy-terminus. Deletion of the $3^{\prime}$ region of prn, encoding P.30, results in the expression of an intracellular form of P.69. Antiserum which recognizes P.30 was raised using synthetic peptides based on the primary amino acid sequence of the region. This anti-P. 30 serum was used in a Western blot analysis of fractionated cells of B. pertussis and $E$. coli harbouring the intact prn gene. The P.30 polypeptide was readily detected in outer membrane fractions prepared from both of these bacterial species, although it could not be shown to be exposed at the cell surface.
\end{abstract}

Keywords: Bordetella pertussis, pertactin, secretion, adhesin

\section{INTRODUCTION}

Members of the genus Bordetella are pathogenic, Gramnegative bacteria that can cause respiratory tract infections in mammalian species. Bordetella pertussis and B. parapertussis are pathogenic for man whereas B. bronchiseptica causes infections in a number of domestic animal species (Goodnow, 1980). The bordetellae colonize their hosts by attaching to the mucosal surfaces in the upper respiratory tract, where they produce a variety of surface-associated and secreted molecules which contribute to their pathogenicity. These products are involved in adhesion to eukaryotic tissues, evasion of host defences and toxicity towards the host (Weiss \& Hewlett, 1986; Sandros \& Tuomanen, 1993). Some of these secreted products, including pertussis toxin (Nicosia et al., 1986), adenylate cyclase (Glaser et al., 1990), pertactin (Charles et al., 1988) and filamentous haemagglutinin (Relman et al., 1990), have been characterized in some detail at the molecular level. Much of this work has been motivated by the search for potentially protective antigens that can be considered for inclusion in acellular whooping cough vaccines (Ad Hoc Committee for the Study of Pertussis Vaccines, 1988; Rappuoli et al., 1991).

The pertactins are a family of surface-associated proteins produced by bordetellae which can induce protective immunity in a variety of model systems when administered as subunit vaccines (Montarez et al., 1985; Shahin et al., 1990; Romanos et al., 1991; Roberts et al., 1992; Charles et al., 1993). Experimental evidence indicates that they play a role in attaching the bordetellae to eukaryotic cells (Leininger et al., 1991, 1992; Roberts et al., 1991). The pertactin polypeptides were named initially after the observed mobility of the species-specific polypeptides on denaturing polyacrylamide gels. Pertactin from $B$. pertussis was named P.69 (Montarez et al., 1985; Charles et al., 1988), from B. parapertussis, P.70 (Montarez et al., 1985; Li et al., 1990) and from B. bronchiseptica, P.68 (Montarez et al., 1985; Li et al., 1992). The proteins can be purified from these organisms and the homogeneous preparations exhibit similar molecular masses on denaturing gels. 


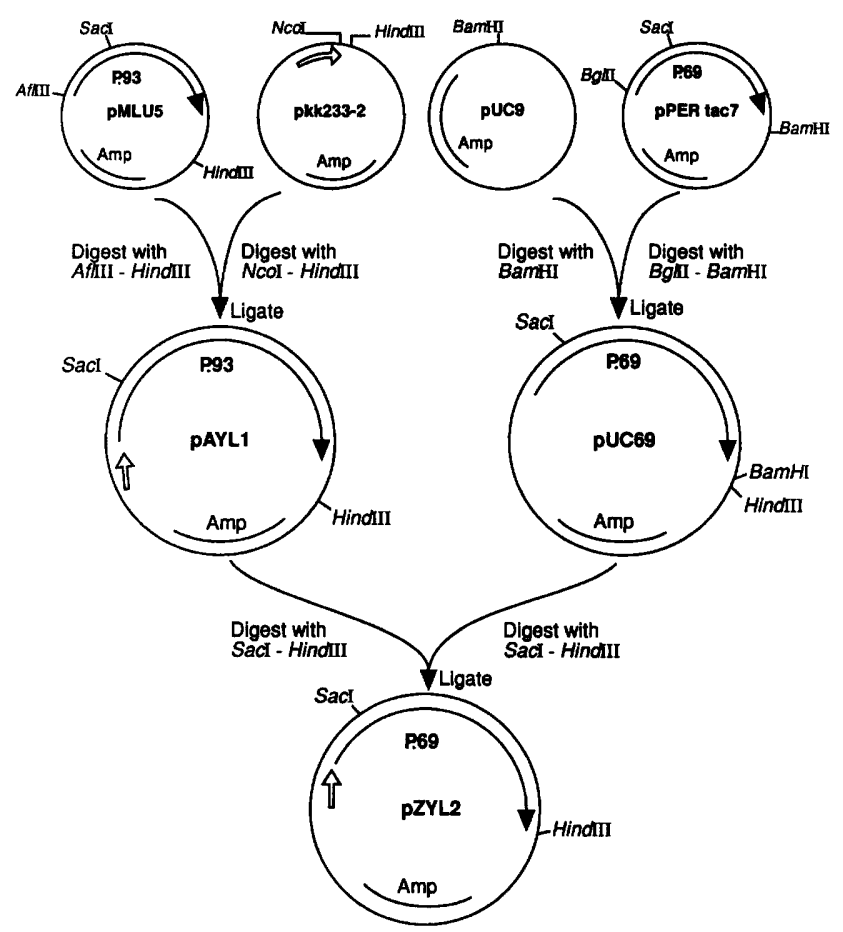

Fig. 1. Scheme for the generation of plasmids PAYL1 and pZYL2. Plasmids were constructed as outlined in Results. Key restriction sites and key manipulation steps are as designated. Solid lines within plasmids designate the position of individual genes. The direction of transcription of particular genes is indicated by the associated arrow where appropriate. The open arrow indicates the position of key promoters driving the expression of prn and derivatives of this gene. P.69 or P.93 designate the corresponding open reading frames. Amp designates the position of the $\beta$-lactamase gene.

The pertactin genes from B. pertussis (Charles et al., 1988), B. parapertussis ( $\mathrm{Li}$ et al., 1992) and B. bronchiseptica (Li et al., 1992) have been cloned and characterized in sequencing and expression studies. Although pertactins can be detected and purified from the surface of the bordetellae as single polypeptides of molecular mass close to $70 \mathrm{kDa}$, their respective genes were found to contain open reading frames encoding considerably larger polypeptides, with predicted molecular masses close to $95 \mathrm{kDa}$. Part of the coding capacity of the genes, known as prn, can be accounted for by an amino-terminal signal sequence. However, amino-terminal analysis of mature proteins has shown that these signal sequences are only 34 amino acids in length (Capiau et al., 1990; Makoff et al., 1990). Interpretation of molecular size is further complicated because the pertactin polypeptides migrate aberrantly in sodium dodecyl sulphate polyacrylamide gels (SDSPAGE). The true molecular mass of the P.69 polypeptide, determined by expressing defined fragments of prn and by carboxy-terminal analysis of purified P.69, is about $60 \mathrm{kDa}$. Therefore, polypeptides of approximately $30 \mathrm{kDa}$ (P.30) are cleaved from the carboxy-terminal of the pertactin precursors (P.93) to generate the mature proteins (P.70, P.69 and P.68).
The expression of the pertactin gene family is under the control of the bvg global regulatory system in the bordetellae (Charles et al., 1988; Arico et al., 1989). bvgregulated promoters express poorly in the absence of the bvg locus, hence expression of the full-length genes in heterologous hosts requires the use of a functional promoter (Makoff et al., 1990). Expression studies, using the full-length prn genes of B. pertussis (Charles et al., 1988), B. bronchiseptica (Li et al., 1992) and B. parapertussis (Li et al., 1990), have shown that proteins of between 93 and $95 \mathrm{kDa}$ can be readily detected in cell extracts and that these precursors are rapidly processed to the mature products. Interestingly, we have shown that when pertactin P.69 is expressed from the untruncated prn gene in heterologous hosts such as salmonellae, the mature protein can be detected at the surface of these cells (Strugnell et al., 1992). To date it has not been possible to identify the cleaved P. 30 product in B. pertussis cells since anti-pertactin antisera only recognized the P.69 domain of the protein.

At present there is no known role for the P.30 carboxyterminal domain of the pertactin protein precursors. The fate of P.30 is unclear and it is not known if it has a role in the export of the mature pertactin polypeptide to the bacterial cell surface. Here we report that P.69, expressed directly as a mature protein from a truncated prn gene lacking the region encoding P.30, is not detectable at the cell surface. In addition we show that P. 30 can be detected in the outer membrane of B. pertussis and E. coli cells when expressed as part of the full-length prn gene.

\section{METHODS}

Bacterial strains and growth conditions. E. coli K12 TG1 and D1210 (Davis et al., 1980) were used for propagation of plasmids. E. coli strains were routinely grown in L-broth or on L-agar (Davis et al., 1980) supplemented with antibiotics where appropriate. Antibiotics were used at a concentration of $100 \mu \mathrm{g} \mathrm{ml}^{-1}$. Minimal medium was prepared as described in Davis et al. (1980). B. pertussis strains BBC26 and BBC44, a prnnegative mutant of BBC26 (Roberts et al., 1991), were cultured on Cohen-Wheeler (CW) agar (Cohen \& Wheeler, 1946) supplemented with $10 \%(\mathrm{w} / \mathrm{v})$ defibrinated horse blood and streptomycin. Isopropyl $\beta$-D-thiogalactopyranoside (IPTG) was obtained from Sigma and was used at a final concentration of $20 \mathrm{mM}$.

Immuno-electron microscopy. Bacteria were prepared for and analysed by electron microscopy as previously described (Strugnell et al., 1992). E. coli cells were treated, before or after embedding, with the P.69-specific monoclonal antibody F6E5. Attached antibody was detected by adding rabbit anti-mouse antibodies tagged with $10 \mathrm{~nm}$ protein A-gold particles (Bioclinical Services).

SDSPAGE, Western blotting and DNA manipulations. Polypeptides were separated using SDS-PAGE according to the method of Laemmli (1970). For Western blotting, gelassociated protein samples were electrophoresed onto nitrocellulose membranes (Towbin et al., 1979) and probed with P.69-specific monoclonal antibody BBO5 (Montarez et al., 1985). After addition of a rabbit anti-mouse immunoglobulinhorseradish peroxidase conjugate, at a concentration of $1 / 1000$ 
(a)

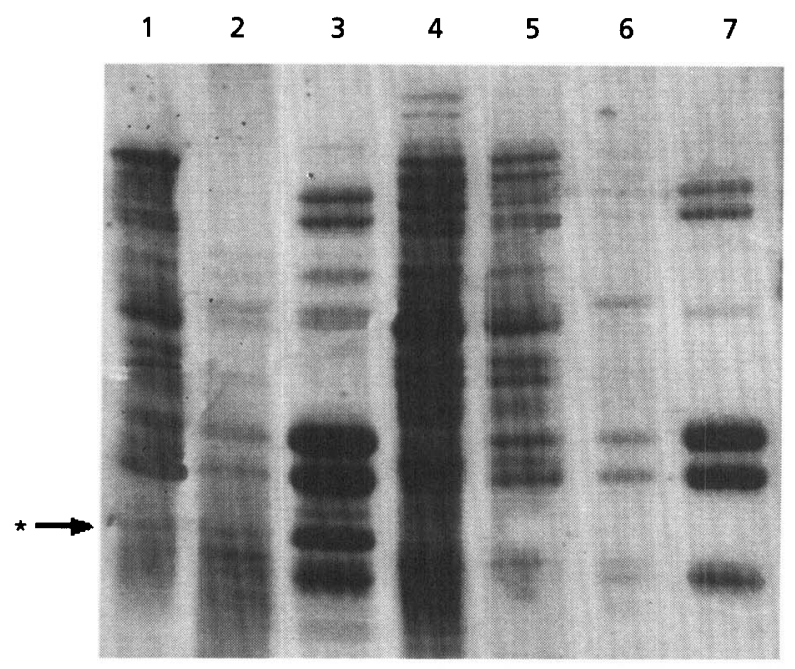

(b)

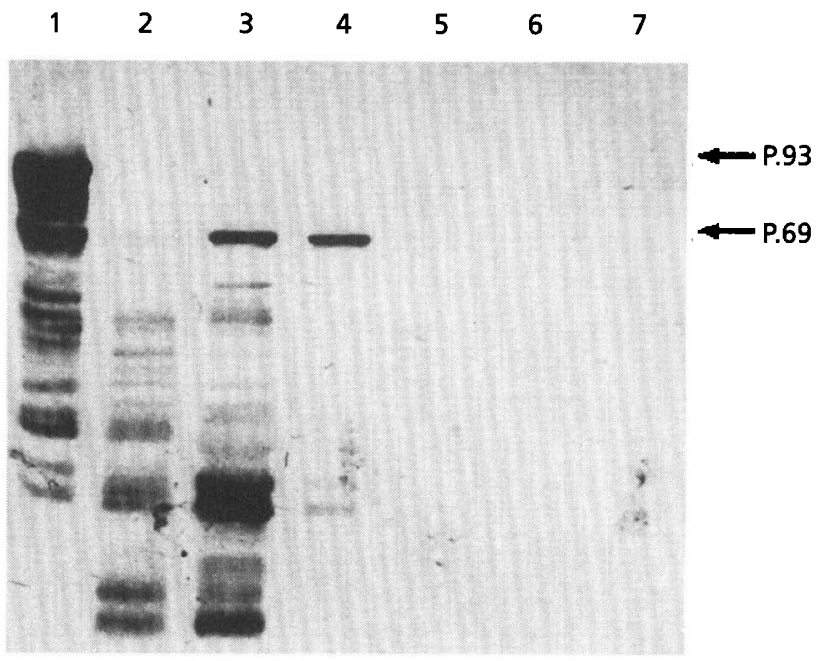

Fig. 2. SDS-PAGE analysis and Western blotting of whole-cell and fractionated preparations of bacteria. All samples were prepared as described in Methods. (a) A representative Coomassie-blue-stained gel (12.5\%, w/v, acrylamide); (b) a representative Western blot of a similar gel probed with monoclonal antibody BBO5. The positions of P.93 and P.69 are indicated on the right. Samples are the same for each panel: Track 1, TG1(pAYL1) whole-cell sonicate; track 2, TG1(pAYL1) Sarkosyl-soluble envelope fraction; track 3, TG1(pAYL1) Sarkosyl-insoluble envelope fraction; track 4, TG1(pAYL1) soluble cell-free fraction; track 5, TG1 envelope fraction; track 6, TG1 Sarkosyl-soluble fraction; track 7, TG1 Sarkosyl-insoluble fraction. The position of the P.30-associated band in track 3 is designated by the asterisk on the left. Additional smaller polypeptides which were recognized by the P.69-specific monoclonal antibody BBO5 were also present in samples prepared from cells which encoded the prn gene. These polypeptides have been shown previously, using microsequencing analysis, to be produced by degradation of pertactin, which is extremely sensitive to proteolytic digestion (Charles et al., 1988).

(DAKO), the bands were visualized using the chromogenic substrate 4-chloro-1-naphthol (Sigma). All enzymes employed for the manipulation of DNA were used according to the manufacturer's instructions or following procedures described in Maniatis et al. (1982).

Peptide synthesis. The following peptides were synthesised using an Applied Biosystems peptide synthesiser (model 481). The sequences correspond to regions within the carboxyterminal region of P.93 (Charles et al., 1988). pepP.30-439 LGELRLNPDAGGAWGRFAQ (residues 6-24); pepP.30-440 FLEPQAELAVFRAGGGAYRA (residues 150-169); pepP.30-441 SKGPKLAMPWTFHAGYRYSW (residues 269288); pepP.30-442 LGGLAGYTRGDRGFTGDGGG（residues 65-84). Peptides were coupled to keyhole limpet haemocyanin and used to immunize mice. The mice were immunized on at least three occasions, at weekly intervals, and serum was harvested several weeks after the initial immunization.

Fractionation of bacterial cells. E. coli strains were cultured overnight in minimal medium, harvested by centrifugation at $3362 \mathrm{~g}$ for $10 \mathrm{~min}$ in a Heraeus $2.0 \mathrm{R}$ centrifuge and the pelleted cells were resuspended in $10 \mathrm{mM}$ sodium phosphate, $\mathrm{pH} 7 \cdot 2$ (ENV buffer). B. pertussis strains were cultured for $2 \mathrm{~d}$ on $\mathrm{CW}$ plates and harvested into ENV buffer in a similar manner. Bacterial cells were disrupted by sonication using $3 \times 30 \mathrm{~s}$ bursts of sonication, followed by $30 \mathrm{~s}$ periods of cooling. Unbroken cells, large cellular debris and insoluble material were pelleted by low-speed centrifugation at $3362 \mathrm{~g}$ for $10 \mathrm{~min}$. Inner- and outer-membrane-enriched fractions were harvested by highspeed centrifugation, at $100000 \mathrm{~g}$ for $45 \mathrm{~min}$, in a Beckman 70.I
Ti rotor. The supernatant containing the cytosolic, extracellular and other soluble components was also harvested. The membrane pellet was resuspended in ENV buffer containing $1 \%$ $(\mathrm{w} / \mathrm{v})$ sodium lauroyl sarcosinate (Sarkosyl) and incubated at room temperature with frequent vortexing to solubilize the inner membrane. The insoluble outer-membrane fraction was re-pelleted by ultracentrifugation at $100000 \mathrm{~g}$ for $90 \mathrm{~min}$, the supernatant was removed and the pellet resuspended in ENV buffer.

\section{RESULTS}

\section{Construction of plasmids encoding pertactin derivatives in $E$. coli}

The construction of the plasmids pAYL1 and pZYL2, which direct the expression of P.93 from the intact prn gene and P.69 from a truncated prn gene, respectively, is shown in Fig. 1. The full-length prn gene comprises an open reading frame of 2730 bp capable of expressing a mature protein of $93447 \mathrm{Da}$ (Charles et al., 1988). In order to construct a plasmid capable of driving the expression of P.93 in E. coli, the full-length prn gene was cloned into the trc-promoter expression plasmid pKK233-2 (Amman \& Brosius, 1985) as an AflIII-HindIII fragment (Fig. 1). The AfIIII site of pMLU5 overlaps the ATG initiation codon of the prn gene. Ligated DNA was transformed into E. coli TG1 and selected on minimal medium. A plasmid with the desired structure was isolated and named pAYL1. E. coli TG1 bacteria harbouring pAYL1 grew 

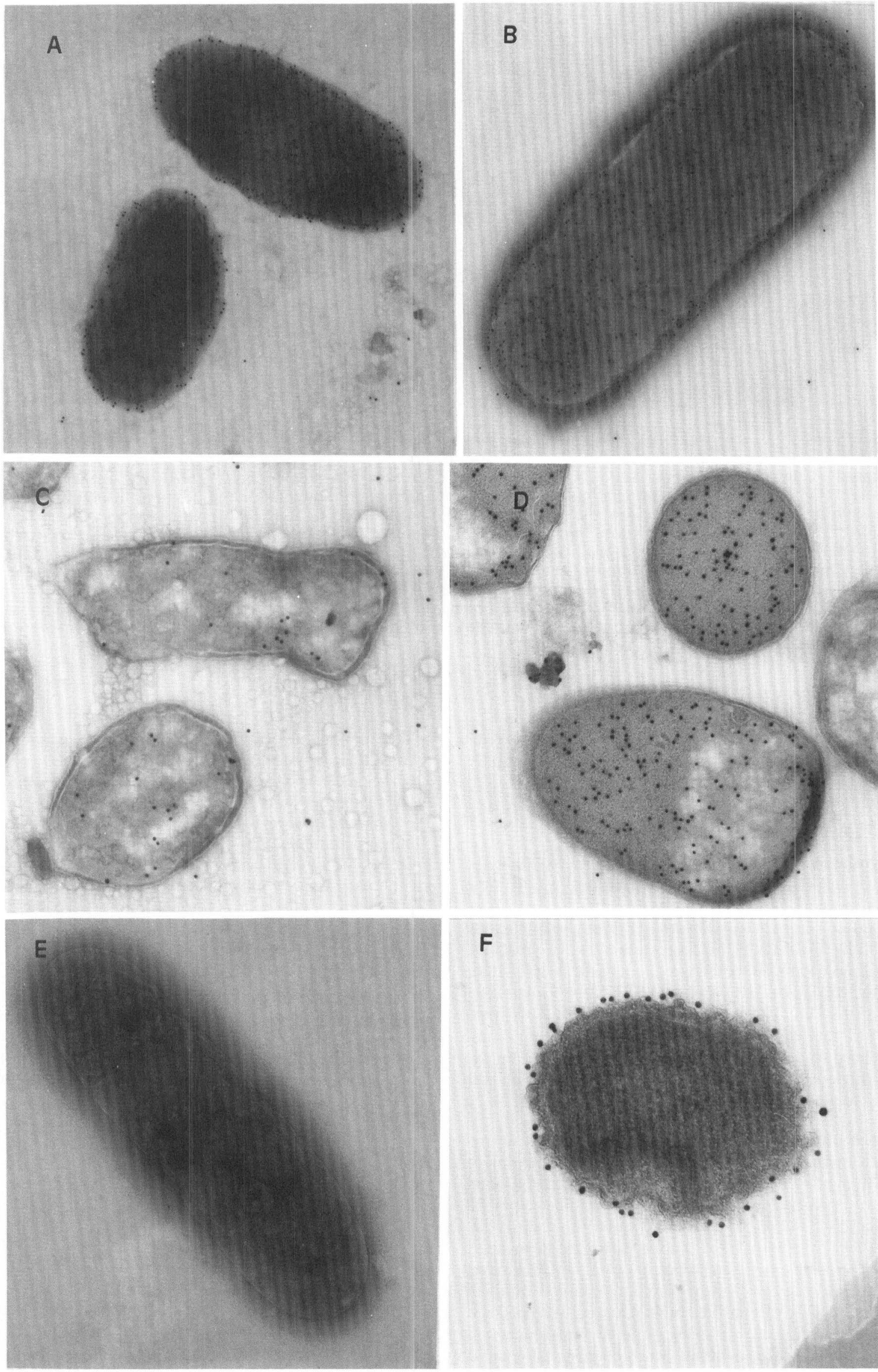

F

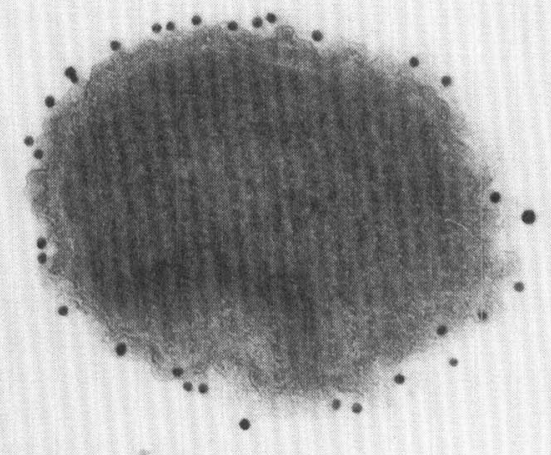


more slowly than their plasmid-free parents in rich medium so the strains were propagated in minimal Casamino acid medium, where the trc promoter was likely to be more efficiently repressed. pAYL1 could be stably propagated under these conditions even though there was still considerable expression of Prn even in the absence of IPTG. However, incorporation of IPTG into the medium, at concentrations sufficient to induce the trc promoter, was lethal to $E$. coli bacteria harbouring pAYL1.

A second plasmid, pZYL2, containing a truncated prn gene lacking the P.30 carboxy-terminal domain of P.93 but still encoding the natural signal sequence, was generated from pAYL1. A $B g / \mathrm{II}-\mathrm{BamHI}$ fragment from pPERtac7 (Makoff et al., 1990) was cloned into pUC18 to generate plasmid pUC69 (Fig. 1). A SacI-HindIII fragment encoding the P.69 open reading frame, complete with the signal sequence but lacking the P.30 coding region, was purified from pUC69 DNA and ligated into SacI-HindIII-digested PAYL1 to generate PZYL2.

\section{Cellular localization of pertactin-derived polypeptides expressed in $E$. coli}

P.69 pertactin, expressed in E. coli TG1 from a truncated $p r n$ gene lacking the signal sequence and P.30 carboxyterminal region, accumulates in the cytoplasm (Charles $e t$ al., 1988). The cellular location of the pertactin derivatives expressed by E. coli TG1 bacteria harbouring either pAYL1 or pZYL2 was determined using a number of different approaches. Initially bacteria were examined for their ability to agglutinate in the presence of anti-pertactin monoclonal or mono-specific polyclonal antisera. These antibodies recognize the mature P.69 form of pertactin and not the P.30 domain (Montarez et al., 1985), E. coli TG1 cells harbouring pAYL1, but not pZYL2, were readily agglutinated with either monoclonal or polyvalent anti-P.69 antibodies. When both TG1 derivatives were subjected to heat shock at $56^{\circ} \mathrm{C}$ for 30 min mature P.69 pertactin could be shocked off the surface of TG1(pAYL1) but not TG1(pZYL2) or D1210(pZYL2) cells (results not shown). This indicates that pertactin is located at the surface of TG1(pAYL1) but not TG1(pZYL2) cells.

To analyse these observations further, E. coli TG1 cells and derivatives harbouring pAYL1 or pZYL2 were fractionated as described in Methods and the cell fractions were analysed using SDS-PAGE and Western blotting with the anti-P.69 monoclonal antibody BBO5. In TG1(pAYL1) whole-cell preparations it was possible to detect both the P.93 and P.69 forms of pertactin using Western blotting (Fig. 2). P.93 was only detected in whole-cell preparations whereas P.69 was detected in cell envelope fractions. TG1(pZYL2) cells expressed only mature P.69. Examination of TG1(pZYL2) cell fractions was complicated by the presence of insoluble P.69 polypeptide, in the form of inclusion bodies. In an attempt to overcome this problem, plasmid pZYL2 was transformed into E. coli strain D1210. In this strain the level of P.69 expression in uninduced cells was lower; inclusion bodies were not detected and P.69 was exclusively associated with the cell envelope (data not shown).

The above results support the hypothesis that mature P.69 pertactin is surface-exposed in E. coli(pAYL1) but not E. coli(pZYL2) cells, although it is envelope-associated in both strains. Further support for this hypothesis was obtained using fluorescence microscopy. Intact TG1(pAYL1) but not TG1(pZYL2) or D1210(pZYL2) cells exhibited surface-associated fluorescence when treated with $\mathrm{BBO} 5$ monoclonal antibody and a fluorescence-labelled pig anti-mouse antibody (results not shown).

\section{Immuno-electron microscopic localization of pertactin}

E. coli TG1, E. coli TG1(pAYL1) and E. coli TG1(pZYL2) bacteria were prepared for microscopy as described in Methods and intact and sectioned cells were labelled with the monoclonal antibody F6E5 followed by colloidal gold-labelled anti-mouse serum. The results obtained are shown in Fig. 3. Sectioned cells of E. coli TG1(pZYL2) exhibited heavy labelling in the cytosol and some of the protein appeared to be in the form of inclusion bodies. No association of labelling with the cell surface of intact bacteria was detected with this strain. In contrast, both sectioned and unsectioned TG1(pAYL1) cells were heavily labelled at the cell surface.

\section{Cellular location and fate of the carboxy-terminal P.30 domain of P.93}

To determine the fate of the carboxy-terminal P.30 polypeptide, antiserum was raised which recognized this domain, using synthetic peptides corresponding to regions of the primary amino acid sequence of P.30. Peptides were coupled to KLH and post-immune serum was monitored for its ability to recognize P.93 expressed from pAYL1 in Western blots. Sera obtained from mice immunized with peptides pepP.30-439 and pepP.30-442 reacted with a P.93 fusion polypeptide (Charles et al., 1988); the serum from mice immunized with the former peptide had the highest titre. This P.30-specific serum was then used to follow the fate of P.30 in E. coli and B. pertussis when expressed from the intact prn gene.

Fig. 4 shows the results of using the anti-P.30 serum in Western blot experiments against cell fractions prepared

Fig. 3. Electron micrographs showing the location of the respective prn gene products on bacterial cells. A, B. pertussis BBC26 unsectioned; B, E. coli TG1(pAYL1) unsectioned and uninduced; C, E. coli TG1(pZYL2) sectioned and uninduced; D, E. coli TG1(pZYL2) sectioned and induced; E, E. coli TG1 unsectioned; F, E. coli TG1(pAYL1) sectioned and uninduced. Cells were probed with pertactin-specific monoclonal antibody F6E5 and immunogold as described in Methods. 


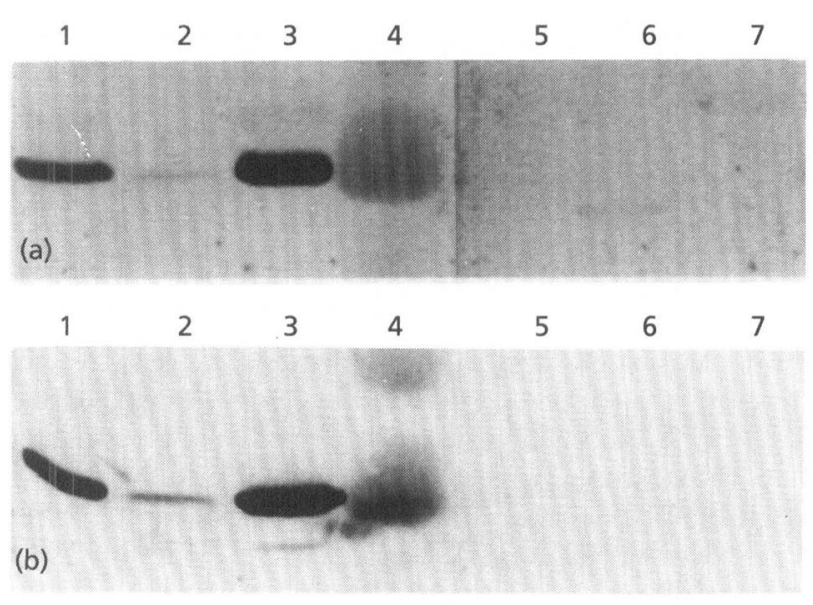

Fig. 4. Localization of pertactin-derived $P .30$ in $B$. pertussis and E. coli. (a) Track 1, B. pertussis BBC26 whole cells; track 2, BBC26 envelope, Sarkosyl-soluble fraction; track 3, BBC26 envelope, Sarkosyl-insoluble fraction; track 4, molecular mass marker carbonic anhydrase (Stained markers, Sigma); track $5, B$. pertussis BBC44 whole cells; track 6, BBC44 envelope, Sarkosylsoluble fraction; track 7, BBC44 envelope, Sarkosyl-insoluble fraction. (b) Track 1, E. coli TG1(pAYL1) whole cells; track 2, E. coli TG1(pAYL1) envelope Sarkosyl-soluble fraction; track 3, E. coli TG1 (pAYL1) envelope Sarkosyl-insoluble fraction: track 4, E. coli TG1 whole cells; track 5, E. coli TG1 Sarkosyl-soluble fraction; track $6, E$. coli TG1 Sarkosyl-insoluble fraction. Nitrocellulose filters were probed with pertactin-specific monoclonal antibody BBO5.

from E. coli TG1 or TG1(pAYL1) and from B. pertussis $\mathrm{BBC} 26$ and $\mathrm{BBC} 44$ (a prn-negative mutant of BBC26). Anti-P.30 serum failed to react with any polypeptides in E. coli TG1 or BBC44 cells in Western blots. However in both $B$. pertussis $\mathrm{BBC} 26$ and $E$. coli TG1 (pAYL1) cells the antiserum reacted with a polypeptide of approximately $32 \mathrm{kDa}$. This corresponded to the expected size of the carboxy-terminal domain of pertactin. Interestingly, this polypeptide was enriched in the outer-membrane fraction of both B. pertussis and E. coli TG1(pAYL1) cells. Also relatively large amounts of a polypeptide of approximately $32 \mathrm{kDa}$ were visible in Coomassie-blue-stained gels of the outer-membrane fractions of TG1(pAYL1) and BBC26 but not TG1 or BBC44 cells (Fig. 2). Attempts were made to demonstrate exposure of P.30 at the cell surface with anti-P.30 serum, by using cell agglutination or ELISA on microtitre plates coated with whole bacteria, but these were not successful.

\section{DISCUSSION}

The pertactin protein of $B$. pertussis has been implicated in the attachment of these organisms to human cells (Leininger et al., 1991; Roberts et al., 1991) and is being considered for inclusion in novel acellular whooping cough vaccines (Rappuoli et al., 1993). Pertactin was originally identified as a polypeptide with an apparent molecular mass of $69 \mathrm{kDa}$ using SDS-PAGE analysis and Western blotting, but sequencing of the gene revealed an open reading frame encoding a polypeptide of $93478 \mathrm{Da}$ (Charles et al., 1988). In this report we have described expression studies carried out in E. coli using the fulllength prn gene and truncated derivatives. By employing specific antisera, which recognize different regions of the pertactin open reading frame, we have shown that, in addition to mature P. 69 pertactin, a $30 \mathrm{kDa}$ polypeptide derived from the carboxy-terminal domain of the prn gene can be detected in both $B$. pertussis and E. coli cells. However this expression was only obtained when driven from the intact gene. Further, expression in the heterologous host E. coli using the intact $p r n$, but not a truncated form of the gene lacking the carboxy-terminal domain, leads to the accumulation of mature P.69 pertactin at the cell surface. The carboxy-terminal P.30 fragment was associated with the outer membranes of $E$. coli and $B$. pertussis when expressed as part of the prn open reading frame, although we were unable to demonstrate that P. 30 is exposed at the bacterial surface using the anti-syntheticpeptide serum. This might merely reflect an inability of the antiserum to recognize a native conformational form of P.30, or alternatively the synthetic peptides selected may not represent surface-located regions of P. 30 .

Pertactin falls into the small group of proteins that can be secreted directly across both the inner and outer membranes of $E$. coli and reach the bacterial cell surface. Mature P.69 was detected at the cell surface of E. coli TG1 only when the full-length $p r n$ gene was used. The presence of the pertactin signal sequence did not appear to be sufficient to direct the mature P. 69 protein to the E. coli cell surface although the protein was associated with the cell envelope. At this stage it is not clear if the P. 30 carboxy-terminal domain plays an active role in targeting P.69 to the cell surface. Carboxy-terminal domains of secreted virulence factors produced by other Gramnegative bacteria such as the IgA proteases of Neisseria gonorrboeae (Pohlner et al., 1987) and Haemopbilus influenzae (Poulsen et al., 1989), and the elastase of Pseudomonas aeruginosa (Kessler \& Safrin, 1988), have been shown to play an active role in the targeting of these proteins. Comparison of the amino acid sequences of P.93, P.69 and P.30 with those of the $\operatorname{IgA}$ proteases, elastase and haemolysin did not reveal any significant homology. Unlike the $\alpha$-haemolysin protein of E. coli, pertactin does not appear to require any specific accessory proteins to enable secretion to occur efficiently. Further experiments will be required to determine the role, if any, of the P.30 region in pertactin secretion.

Since no specific serum has been available, it has been impossible previously to determine the fate of P.30 in either B. pertussis or E. coli cells. It was surprising to find that the domain is associated with the outer membrane of these bacteria and is present in considerable quantities, even in natural B. pertussis cells. P.69 can be readily purified from B. pertussis free of P.30, and pure P.69 has been shown both to act as an adhesin (Leininger et al., 1991) and to be effective as a subunit vaccine against aerosol challenge of mice with B. pertussis (Shahin et al., 1990; Romanos et al., 1992; Roberts et al., 1992). The function of P.30 within the cell envelope remains unclear. 
The polypeptide does contain an arginine-glycine-aspartic acid motif, commonly found on integrin binding proteins (Hynes, 1992) but such a role has not been proven for this region of P.30. Indeed P.30 may play no role in attachment to eukaryotic cells, although this possibility is worth investigating. In addition further characterization of this region may help whooping cough vaccine development.

Pertactin P.69 is one of a family of closely related proteins expressed by the bordetellae. Pertactins are detected as P.69 in B. pertussis, P.70 in B. parapertussis (Li et al., 1990) and P.68 in B. bronchiseptica (Montarez et al., 1985; Li et al., 1992). Sequencing of these genes has shown that they all contain an open reading frame encoding a larger precursor polypeptide of similar size. Thus it appears that the structure of these genes is highly conserved in the bordetellae. In fact the carboxy-terminal region is the most highly conserved region between the pertactins from the three Bordetella species (Li et al., 1992), suggesting that the function of this region is very important. The reason and process by which the pertactin precursor protein is cleaved is not known, although a number of potential protease cleavage sites have been identified in the sequence (Makoff et al., 1990). Interestingly, when P.69 pertactin was expressed using the intact prn gene in the eukaryotic baculovirus system a similar processing of P.93 to P.69 was observed (Charles et al., 1993). Thus it is possible that the cleavage of pertactin precursor is effected by a general protease activity or alternatively the protein may be auto-proteolytic. Further analysis will be required before we can determine the roles of the various domains of the pertactin proteins in secretion, pathogenicity and immunity.

\section{ACKNOWLEDGEMENTS}

Gordon Dougan was supported by a programme grant from the Wellcome Trust.

\section{REFERENCES}

Ad Hoc Committee for the Study of Pertussis Vaccine (1988). Placebo-controlled trial of two acellular pertussis vaccines in Sweden - protective efficacy and adverse events. Lancet i, 955.

Amman, E. \& Brosius, J. (1985). 'ATG' vectors for regulated highlevel expression of cloned genes in Escherichia coli. Gene 40, 183-189.

Arico, B., Miller, J., Roy, C., Stibitz, S., Monack, D., Falkow, S., Gross, R. \& Rappuoli, R. (1989). Sequences required for expression of Bordetella pertussis virulence factors share homology with procaryotic signal transduction molecules. Proc Natl Acad Sci US A 86, 6671-6675.

Capiau, C., Carr, S. A., Hemling, M. E., Plainchamp, D., Conrath, K., Hauser, P., Simoen, E., Comerbach, M., Roelant, P., Desmons, P., Permanne, P. \& Petre, J. O. (1990). Purification, characterisation, and immunological evaluation of the $69-\mathrm{kDa}$ outer membrane protein of Bordetella pertussis. In Proceedings of the Sixth International Symposium on Pertussis, pp. 75-86. Edited by C. R. Manclark. Bethesda, MD: Department of Health and Human Services, United States Public Health Service. DHHS Publication no. (FDA) 901164.

Charles, I. G., Dougan, G., Pickard, D., Chatfield, S. N., Smith, M.,
Novotny, P., Morrissey, P. M. \& Fairweather, N. F. (1988). Molecular cloning and characterisation of a protective outer membrane protein P.69 from Bordetella pertussis. Proc Natl Acad Sci US A 86, 3554-3558.

Charles, I. G., Rodgers, B., Musgrave, S., Peakman, T. C., Chubb, A., Fairweather, N. F., Dougan, G. \& Roberts, M. (1993). Expression of the P.69 pertactin from Bordetella pertussis in a baculovirus/insect cell expression system: protective properties of the recombinant protein. Res Microbiol 144, 681-690.

Cohen, S. M. \& Wheeler, M. W. (1946). Pertussis vaccine prepared from phase 1 cultures grown in fluid medium. Am J Public Health 36, 371-377.

Davis, R. W., Botstein, D. \& Roth, J. R. (1980). Advanced Bacterial Genetics. A Manual for Genetic Engineering. Cold Spring Harbor, NY: Cold Spring Harbor Laboratory.

Glaser, P., Sakamoto, H., Bellalou, J., Ullman, A. \& Danchin, A. (1990). Secretion of cytolysin, the calmodulin-sensitive adenylate cyclase-hemolysin bifunctional protein of Bordetella pertussis. EMBO $J$ 7, 3997-4044.

Goodnow, R. A. (1980). Biology of Bordetella bronchiseptica. Microbiol Rev 44, 722-738.

Hynes, R. O. (1992). Integrins, versatile, modulation and signalling in cell adhesion. Cell 69, 11-25.

Kessler, E. \& Safrin, M. (1988). Synthesis, processing, and transport of Pseudomonas aeruginosa elastase. J Bacteriol 170, 5241-5247.

Laemmli, U. K. (1970). Cleavage of structural proteins during the assembly of the head of bacteriophage T4. Nature 227, 680-682.

Leininger, E., Roberts, M., Kenimer, J. G., Charles, I. G., Fairweather, N. F., Novotny, P. \& Brennan, M. J. (1991). Pertactin, an Arg-Gly-Asp-containing Bordetella pertussis surface protein that promotes adherence of mammalian cells. Proc Natl Acad Sci US A 88, 345-349.

Leininger, E., Ewanowich, C. A., Bhargava, A., Peppler, M. S., Kenimer, J. G. \& Brennan, M. J. (1992). Comparative roles of the Arg-Gly-Asp sequence present in the Bordetella pertussis adhesins pertactin and filamentous haemagglutinin. Proc Natl Acad Sci US A 88, 345-349.

Li, L. J., Dougan, G., Novotny, P. \& Charles, I. G. (1990). Pertactin, an outer membrane protein from Bordetella parapertussis: cloning, nucleotide sequence and surface expression in Escherichia coli. Mol Microbiol 5, 409-417.

Li, J. L., Fairweather, N. F., Novotny, P., Dougan, G. \& Charles, I. G. (1992). Cloning, nucleotide sequence and heterologous expression of the protective outer membrane protein P.68/pertactin from Bordetella bronchiseptica. J Gen Microbiol 138, 1697-1705.

Makoff, A. J., Oxer, M. D., Ballantine, S. P., Fairweather, N. F. \& Charles, I. G. (1990). Protective surface antigen P.69 of Bordetella pertussis: its characterisation and high level synthesis in Escherichia coli. Bio/Technology 8, 1030-1032.

Maniatis, T., Fritsch, E. F. \& Sambrook, J. (1982). Molecular Cloning: a Laboratory Manual. Cold Spring Harbor, NY : Cold Spring Harbor Laboratory.

Montarez, J. A., Novotny, P. \& Ivanyi, J. (1985). Identification of a 68 kilodalton protective antigen from Bordetella bronchiseptica. Infect Immun 47, 744-751.

Nicosia, A., Perugini, M., Franzini, C., Casagli, M. C., Borri, M. G., Antoni, G., Almoni, M., Neri, P., Ratti, G. \& Rappuoli, R. (1986). Cloning and sequencing of the pertussis toxin genes: operon structure and gene duplication. Proc Natl Acad Sci USA 83, 4361-4365.

Pohlner, J., Hatler, R., Beyreuther, K. \& Meyer, T. F. (1987). Gene 
structure and extracellular secretion of Neisseria gonorrboeae IgA protease. Nature 325, 458-460.

Poulsen, K., Brandt, J., Hjorth, P., Thogersen, H. C. \& Kilian, M. (1989). Cloning and sequencing of the immunoglobulin A1 protease gene (iga) of Haemopbilus influenzae serotype b. Infect Immun 57, 3097-3105.

Rappuoli, R., Pizza, M., Podda, A., De Magistris, M. T. \& Nencioni, L. (1991). Towards third generation whooping cough vaccines. Trends Biotechnol 9, 232-239.

Relman, D., Tuomenen, E., Falkow, S., Golenbock, T., Saukkonen, K. \& Wright, S. D. (1990). Recognition of a bacterial adhesin by an integrin: macrophage CR3 binds filamentous hemagglutinin of Bordetella pertussis. Cell 61, 1375-1382.

Roberts, M., Fairweather, N. F., Leininger-Zapata, E., Brennan, M. J., Pickard, D., Hewlett, E. L., Robinson, A., Hayward, C., Dougan, G. \& Charles, I. G. (1991). Construction and characterisation of Bordetella pertussis mutants lacking the vir-regulated P.69 outer membrane protein. Mol Microbiol 5, 1393-1404.

Roberts, M., Tit, J. P., Fairweather, N. F., Dougan, G. \& Charles, I. G. (1992). Recombinant P.69/pertactin: immunogenicity and protection of mice against Bordetella pertussis infection. Vaccine 10, 43-48.

Romanos, M. A., Clare, J. J., Beesley, K. M., Rayment, F. B.,
Ballantine, S. P., Makoff, A. J., Dougan, G., Fairweather, N. F. \& Charles, I. G. (1992). Recombinant Bordetella pertussis pertactin (P.69) from the yeast Pichia pastoris: high level production and immunological properties. Vaccine 9, 901-906.

Sandros, J. \& Tuomenen, E. (1993). Attachment factors of Bordetella pertussis: mimicry of eucaryotic cell recognition molecules. Trends Biotechnol 1, 192-196.

Shahin, R. D., Brennan, M. J., Li, Z. M., Meade, B. D. \& Manclark, C. R. (1990). Characterisation of the protective capacity of the $69 \mathrm{kDa}$ outer membrane protein of Bordetella pertussis. J Exp Med 171, 63-73.

Strugnell, R. A., Dougan, G., Chatfield, S., Charles, I. G., Fairweather, N. F., Tit, J., Li, J. L. \& Roberts, M. (1992). Characterisation of a Salmonella typhimurium aro vaccine strain expressing the P.69 antigen of Bordetella pertussis. Infect Immun 60, 3994-4002.

Towbin, H., Staehelin, T. \& Gordon, J. (1979). Electrophoretic transfer of proteins from polyacrylamide gels to nitrocellulose sheets : procedures and some applications. Proc Natl Acad Sci USA 76, 4350-4354.

Weiss, A. A. \& Hewlett, E. L. (1986). Virulence factors of Bordetella pertussis. Annu Rev Microbiol 40, 661-686.

Received 9 May 1994; revised 12 July 1994; accepted 1 August 1994. 